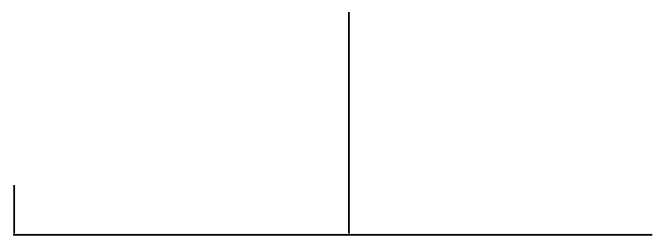

Rev. Latinoam. Psicopat. Fund., São Paulo, v. 13, n. 3, p. 512-516, setembro 2010

Tentativa frustrada de assassinato da psicanálise

Agnès Aflalo

Paris: Psyché/Ed. Cécile Defaut, 2009, 177p.

\title{
Tentativa frustrada de assassinato da psicanálise
}

Advirto o leitor de que é preciso ter muito fôlego ou terminará a leitura desse livro completamente ofegante. A escrita de Agnès não deixa espaço para que o leitor se perca em seus devaneios ou salte algumas páginas. O ritmo da narrativa repercute a tensão, a expectativa e a pressa em concluir. A temporalidade que ela imprime ao texto não é do pensamento, é a da ação. É um livro que desperta, convoca, impele a agir. Composto de sete partes, dois anexos e extensa bibliografia, foi prefaciado pelo filósofo Bernard HenriLèvy. BHL afirma que "era preciso que esse livro fosse escrito", não somente porque relata uma batalha de ideias travada na França como também porque ele desnuda uma ideologia ainda em vias de constituir-se, mas cujo potencial nocivo não foi completamente avaliado. 
O primeiro capítulo, intitulado "A emenda" é denso de referências precisas aos acontecimentos recentes que, em 2003, ensejaram uma batalha dos psicanalistas de orientação lacaniana contra a emenda do parlamentar, Mr. B. Accoyer, que "pretendia impor uma regulamentação do exercício das psicoterapias sem acordo prévio com os praticantes. Equivale a dizer que ele representava uma ameaça para o futuro da psicanálise. Com efeito, alguns dias mais tarde, um vasto movimento de opinião, conduzido por Jacques Alain Miller, manifestava sua viva inquietação por todo lado na França." A essa tentativa frustrada de assassinato, não faltou a cumplicidade de "publicações hostis à psicanálise, que usurpam o termo 'ciência' para dele se prevalecerem." Falsos saberes, sedutores, que fazem ar de saberes científicos e sob o pretexto de assegurar os direitos do consumidor, confiscam-lhe o direito de escolha e as liberdades democráticas.

Em outubro de 2003, o Ministério francês anuncia a elaboração de um "Plano global de saúde mental" (Plan Clérry-Melin), produzido sem que representantes da psicanálise, das psicoterapias e da psicologia clínica tivessem nele qualquer participação. O plano e a emenda eram duas faces de um mesmo projeto: avaliar as psicoterapias, enquadrá-las e submetê-las ao poder médico. Psiquiatras se tornariam coordenadores regionais e decidiriam autoritariamente qual profissional "psi” um cidadão deveria consultar. A opinião esclarecida, não tardou a reagir comparecendo aos "Fóruns Psy" organizados a cada quinze dias. Pronunciaramse diante do numeroso público, filósofos, escritores, artistas e intelectuais reconhecidos, como o próprio Bernard Henri-Lèvy, Jean-Claude Milner, Phillipe Soller e Catherine Clément. Políticos de tendências diversas, tais como François Bayrou, Renaud Dutreil, Jean-Michel Fourgous e Bernard Kouchner, se fizeram presentes. Igualmente intervieram nos fóruns diversos jornalistas como Jean Pierre Elkabbach e Edwy Plenel. Elizabeth Roudinesco tornou pública a notícia de que os representantes de importantes sociedades psicanalíticas - a Sociedade Psicanalítica de Paris, Associação Psicanalítica da França, a Organização Psicanalítica de língua francesa, a Associação Lacaniana Internacional e a Sociedade de Psicanálise Freudiana - consentiam em sujeitar-se aos planos do Estado. "Bons lacanianos", como Bernard Brusset da SPP, apressaram-se em apoiar a política de regulamentação e a sujeição das práticas "psi” ao poder médico.

Essencialmente, como bem demonstra Agnès Aflalo, sob o pretexto de esclarecer o público e disciplinar o exercício das diferentes práticas “psi”, tratouse de uma tentativa de demonstrar que as terapias baseadas na palavra não têm efeito terapêutico sobre os sintomas que afligem o público, supostamente, mal informado e fácil de iludir por diversos charlatães. Os psicoterapeutas do futuro deveriam vir a se formar em institutos de formação, como os que existem nas Faculdades de Medicina. Eles seriam treinados para exercer as terapias cognitivo- 
-comportamentais, assim como a psicanálise e outras especialidades dentro do quadro da formação psiquiátrica. Arquitetava-se um plano para liquidar com as instituições psicanalíticas, assimilando-as aos cursos universitários. Em fevereiro de 2004, o INSERM, ${ }^{1}$ a pedido da Direção Geral da saúde, publica sua avaliação de três psicoterapias. As TCC foram consideradas as mais eficientes, muito embora a psicanálise não tenha sido sequer avaliada.

Em fevereiro de 2005 o Ministro da Saúde, Pierre Douste-Blazy compareceu ao V Fórum Psy, intitulado "O direito ao segredo". Contestou a ideia de que o sofrimento psíquico possa ser medido e avaliado. Rejeitou o relatório do INSERM e comprometeu-se em retirá-lo do site do Ministério da Saúde. A reação não demorou. Adeptos do TCC publicaram o Livro negro da psicanálise que, por sua vez, ensejou como resposta uma série de textos curtos, claros e críticos sobre as TCC e que intitulou-se $O$ antilivro negro da psicanálise. A batalha prosseguiu e levou a École de la Cause Freudienne a obter uma vitória de peso. Foi reconhecida em 5 de março de 2006 uma instituição de utilidade pública. Finalmente, no começo de março de 2009 uma nova emenda, defendida perante a Assembléia, pessoalmente, por Mme Roselyne Bachelot - nova Ministra da Saúde - substituiu a lei Accoyer.

Se vocês acreditam que essa epopéia é tão somente um delírio paranoico de um certo número de analistas iconoclastas de orientação lacaniana, é preciso ler com atenção e seriedade - se conseguirem conter o riso - os dois capítulos que se seguem. A autora examina minuciosamente os fundamentos epistêmicos da releitura da psicanálise freudiana por ninguém menos que o ex-presidente da IPA, Daniel Widlöcher. Empenhado numa curiosa "atualização" dos conceitos psicanalíticos, ele os retalha e recorta revelando sua incrível unicidade. O inconsciente, o desejo, a pulsão, a angústia, os afetos, a transferência e a interpretação reduzem-se ao pensamento. A descoberta freudiana pode ser localizada inteiramente no campo das ciências naturais. Widlöcher suprime todos os obstáculos - em particular, aqueles que derivam do campo da fala e da linguagem - e obtém a naturalização do inconsciente e do desejo. A psicanálise widlöchiana opera milagres, pois ajusta-se perfeitamente aos parâmetros pseudocientíficos das terapias cognitivo-comportamentais e abre-se ao diálogo com as neurociências. Sua hermenêutica prescinde da linguística, pois tornar consciente o não consciente equivale a conferir sentido ao pensamento-ação. E, para galgar mais um degrau na escala das ciências, basta servir-se das

1. Institut National pour la Santé, l'enseignement et la recherche medicales. 
neurociências como álibi para propor a equivalência entre o pensamento e o cérebro ou, melhor ainda, entre o estado da matéria cerebral e a atividade do pensamento. Desnecessário acrescentar que Agnès Aflalo nos apresenta essas conclusões com as devidas referências precisas aos textos do autor.

Em síntese, o leitor poderá conferir por si mesmo. Existe um laço entre a expansão do desejo de controle avaliacionista por parte do poder público e esse lamentável trabalho de revisão dos fundamentos da doutrina freudiana que visa adaptá-la ao gosto pseudocientífico de nossa civilização.

No esforço de elucidar o advento de uma nova onda - neste imenso oceano de falsa ciência em que tantas vezes já submergiu a civilização ocidental -, Agnès Aflalo redigiu três artigos, originalmente publicados na revista Le Nouvel Âne e que, reescritos, configuram os três capítulos seguintes. O capítulo IV analisa as terapias cognitivo-comportamentais. Ele revela a ligação estreita entre os pressupostos metodológicos dessa abordagem e a objetificação do novo "homem sem qualidades" talhado sob medida pelo gosto pela mensuração das almas. Privados da fala, que é onde comparece a singularidade do desejo e a responsabilidade pelo gozo, o "homem sem qualidades" parece mais dócil à padronização. O capítulo $\mathrm{V}$ versa sobre os efeitos do declínio epistemológico da fina semiologia - que alicerçou a clínica psiquiátrica, e na qual se basearam tanto Freud quanto Lacan - substituída pela metodologia estatística que domina a epidemiologia em saúde mental. Em lugar do diagnóstico fundado na estrutura do sintoma, a mentalidade epidemiológica quer impor a classificação dos transtornos mentais pulverizados em fenômenos dispersos, pois destituídos de sua lógica própria. O capítulo VI aborda o tema da psiquiatria biopsicossocial. Não deixamos de reconhecer nele a crítica de inspiração foucaultiana aos biopoderes, que visam controlar as populações perigosas, forjar novos hábitos, perseguir o gozo inútil, reduzir os riscos e incrementar uma política que promove um ideal de saúde sem sujeito.

Finalmente, o capítulo VII retoma a via aberta por Lacan quando, em seu seminário XVI, ele antecipava que o saber entraria no mercado e tornar-se-ia uma mercadoria que se compra e se vende, uma vez que fosse reduzido ao diploma universitário. Sem dúvida, há setores do discurso universitário que trabalham para impor a todos os segmentos sociais, a todas as políticas e a todas as atividades uma mesma exigência: "qualidade total". Suprimir as liberdades democráticas e substituí-las pela satisfação do consumidor, penso que se pode encontrar nesse slogan o verdadeiro regente dessa grande orquestra de tantos pseudossaberes e de tão grande poder acéfalo.

Esse livro chega em bom momento. Mais uma vez ressurge a tentativa de submeter os psicólogos clínicos e psicanalistas ao poder discricionário do médico, 


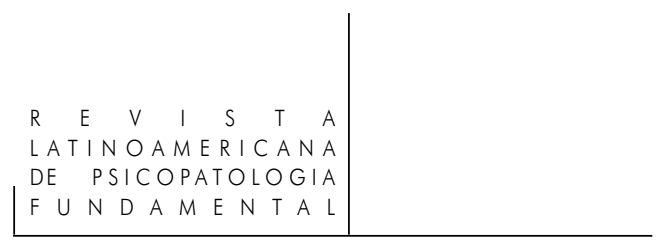

em terras brasileiras. Já nos habituamos a isso. É incrível que profissionais sérios, formados para o exercício responsável da medicina, pretendam estar em condições de indicar a que tipo de psicoterapia um paciente deve se submeter. Enquanto nos preparamos para mais essa batalha, a leitura desse livro pode nos prover com excelente munição.

\section{Tania Coelho dos Santos}

Pós-Doc no Départmant de Psychanalyse da Universidade Paris-VIII, França; Doutorado em Psicologia Clínica pela Pontifícia Universidade Católica do Rio de Janeiro - PUC-RJ (Rio de Janeiro, RJ, Brasil); Professora Associada do Programa de Pós-Graduação em Teoria Psicanalítica do Instituto de Psicologia da Universidade Federal do Rio de Janeiro - UFRJ (Rio de Janeiro, RJ. Brasil); Coordenadora do Núcleo Sephora de Pesquisa sobre o Moderno e o Contemporâneo (Rio de Janeiro, RJ. Brasil); Membro da Escola Brasileira de Psicanálise (Rio de Janeiro, RJ), da Associação Mundial de Psicanálise e da Associação Universitária de Pesquisa em Psicopatologia Fundamental (São Paulo, SP, B rasil)

Rua Prof. Julio Lohman, 430 - Joatinga

22611-170 Rio de Janeiro, RJ

Fonefax: (21) 493-6306

e-mail: taniacs@openlink.com.b 